\title{
Science benefits despite cuts elsewhere
}

\section{Tokyo}

SCIENCE, particularly basic science, made a few small gains even from Japan's most stringent budget for almost thirty years.

After a long battle against the opposition parties in the Diet, with the April budget deadline looming ever closer, the government has finally won agreement for a 0.5 per cent cut in public expenditure during fiscal year 1984-85. Even so, the government will still be short of cash, and will have to issue bonds worth around $\mathrm{Y} 2 \times 10^{13}$ $\left(\$ 8 \times 10^{19}\right)$ to cover expenditure, adding to the Y $10^{14}$ of public debt already incurred.

Expenditure increases have been granted in only a few areas: defence (plus 5-6 per cent), overseas development aid (plus 6 per cent) and science and technology (plus 0.7 per cent). None of the big three science and technology bodies shown in the table - the Science and Technology Agency (STA), the Ministry of Education, Culture and Science (MESC) and the Ministry of International Trade and Industry (MITI) - has gained much in total, but all have managed to protect their basic research programmes.

The biggest increase of all is for the new projects in areas related to computers and the life sciences. MITI's fifth generation computer project, the plan to build an "intelligent" computer which has sent Western governments scrambling to support artificial intelligence research, receives an 88 per cent budget increase. Close behind comes a 43 per cent increase, within MITI's large-scale industrial technologies programme, for research towards building the world's most powerful supercomputer. The goal is a machine capable of 10,000 million floating point operations per second, with applications in areas such as weather forecasting and the design of nuclear warheads.

All ministries, including the Ministry of Agriculture, Forestry and Fisheries and the Ministry of Health and Welfare (MHW), have increased expenditure in the life sciences, concentrating on biotechnology and cancer research. Precise budget increases are hard to calculate, for Prime Minister Nakasone's approval in June last year of a comprehensive "ten-year strategy for cancer control' has led to a recategorization of some funds for life science research.

There is little doubt, however, that total expenditure on fundamental research into molecular biology and the treatment of cancer is growing now that each ministry has established special "anticancer" funds (MHW Y1,600 million, MESC Y1,200 million, STA Y7,700 million, STA Radiological Institute Y400 million) as well as supporting cancer-related research in their general budgets. Research is being coordinated under seven main themes: oncogenesis, carcinogenesis, early diagnosis, chemotherapy, radiotherapy and immuno-modulation and the use of monoclonal antibodies.

The budgets of the various agencies of the Japanese Government are as follows:

Science and Technology Agency. The budget for "special promotion funds", the interministerial grants for basic research thought vital to Japan's long-term prosperity which are given out directly by the prime minister's own advisory council, is further increased. Priorities are now recombinant DNA research, the development of new materials and cryogenic tech-

Japanese science budget

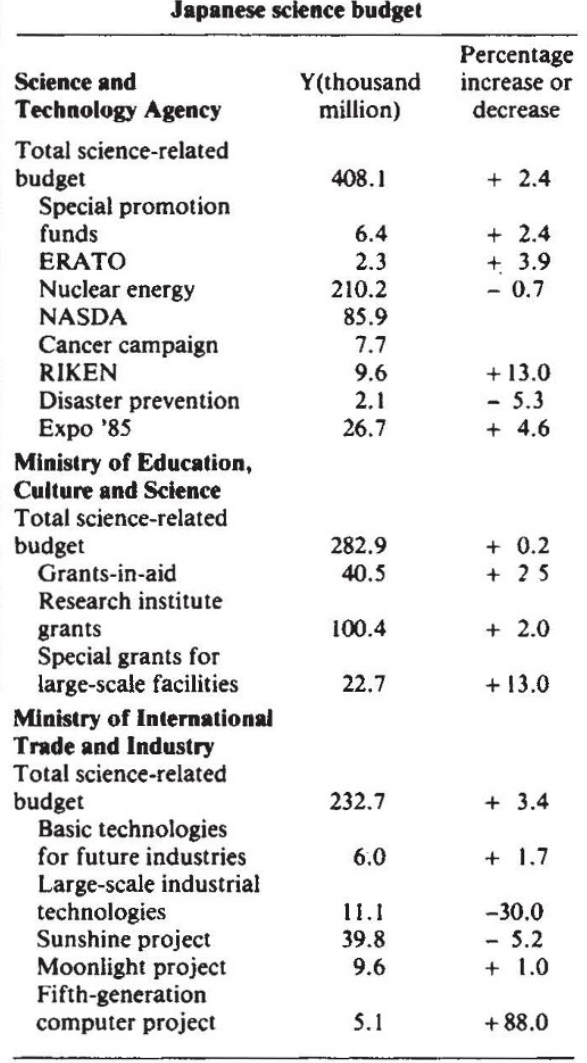

nologies. But there is also an increase for Project ERATO which, by its support for work by small interdisciplinary groups on novel and sometimes eccentric themes, sets out deliberately to stimulate creativity.

The budget for research at STA's two massive nuclear energy institutes, the Power Reactor and Nuclear Fuel Development Corporation and the Japan Atomic Energy Research Institute, is slightly down but the figures conceal a large increase (33 per cent) for Project Monju - the building of a prototype $300 \mathrm{MW}$ fast-breeder reactor by the late 1980 s.

Expenditure on the commercial space programme by the National Space
Development Agency (NASDA) remains static although big increases are likely next year as the plan to build the $\mathrm{H} 2$ rocket, capable of putting $200-\mathrm{kg}$ satellites into orbit, gets under way (see Nature 308, 3; 1984).

For the second year running, a big chunk of STA's budget is swallowed by preparations for Expo '85, the international exposition on the theme of "Science and Technology for Man at Home" which will open in Tsukuba Science City in March next year. Expenditure on Expo will practically cease in the next fiscal year and various groups are already eyeing the spare cash that will then become available.

Of the research corporations attached to STA, the Institute of Physical and Chemical Sciences (RIKEN) has the largest budget increase. Part of this represents continuing investment in the construction of a heavy ion accelerator.

Ministry of Education, Culture and Science. Grants to research institutes and grants in aid of research both increase a little but there is a bigger increase in "special funds" for large-scale facilities. Much of the extra will go to the High-Energy Physics Laboratory (KEK) for the $30-\mathrm{GeV}$ per beam electron-positron collider (TRISTAN) at Tsukuba Science City. The project is on target, with the first results still expected in autumn 1986.

Also blessed among MESC's research laboratories are the National Institute of Genetics, which acquires the coveted status of a National Research Institute for Joint Use by Universities (see Nature 305, 372; 1981); the Institute for Space and Aeronautic Science which receives a $10-15$ per cent budget increase, mostly earmarked for the launch of the Halley's comet probe, Planet-A; the University of Tokyo's Astronomical Observatory, which gains further investment in the Nobeyama millimetrewave telescope; Kyoto University's Institute for Mathematical Sciences, where a new section of algebraic analysis is to be set up; and Osaka University's Microbiological Institute, which adds a section to study the molecular biology of cancer.

Ministry of International Trade and Industry. The ministry's "Basic Technologies for Future Industries" programme, made up of long-term research projects on biotechnology, new materials and new electronic devices, continues to be fully supported, giving credence to the avowed aim not to cut back on fundamental research even when funds are tight. Some of the more conventional programmes, the Sunlight programme for the development of new energy sources and the Moonlight programme for energy conservation, have done less well. Within the Large-Scale Industrial Technologies programme, which covers nine projects ranging from robot flexible manufacturing systems to computerized sewing systems, only the supercomputer project and the "robots for extreme environments" projects will see budget increases.

Alun Anderson 